\title{
A Novel Methoxybenzyl 5-Nitroacridone Derivative Effectively Triggers G1 Cell Cycle Arrest in Chronic Myelogenous Leukemia K562 Cells by Inhibiting CDK4/6-Mediated Phosphorylation of $\mathbf{R b}$
}

\author{
Bin Zhang ${ }^{1,2}$, Ting Zhang ${ }^{1}$, Tian-Yi Zhang ${ }^{1}$, Ning Wang ${ }^{2,3, *}\left(\mathbb{0}\right.$, Shan $\mathrm{He}^{1}{ }^{1}$, Bin Wu ${ }^{4}$ \\ and Hai-Xiao Jin ${ }^{1, *}$ \\ 1 Li Dak Sum Yip Yio Chin Kenneth Li Marine Biopharmaceutical Research Center, \\ Department of Marine Pharmacy, College of Food and Pharmaceutical Sciences, Ningbo University, \\ Ningbo 315800, Zhejiang, China; binzhang86@126.com (B.Z.); zt326311@163.com (T.Z.); \\ zty3215310hdzf@163.com (T.-Y.Z.); heshan@nbu.edu.cn (S.H.) \\ 2 State Key Laboratory of Chemical Oncogenomics, Key Laboratory of Chemical Biology, \\ Tsinghua Shenzhen International Graduate School, Shenzhen 518055, China \\ 3 Institute of Drug Discovery Technology, Ningbo University, Ningbo 315800, Zhejiang, China \\ 4 Ocean College, Zhejiang University, Hangzhou 310058, China; wubin@zju.edu.cn \\ * Correspondence: wangning2@nbu.edu.cn (N.W.); jinhaixiao@nbu.edu.cn (H.-X.J.)
}

Received: 29 June 2020; Accepted: 17 July 2020; Published: 18 July 2020

check for updates

\begin{abstract}
Chronic myeloid leukemia (CML) is a malignant tumor caused by the abnormal proliferation of hematopoietic stem cells. Among a new series of acridone derivatives previously synthesized, it was found that the methoxybenzyl 5-nitroacridone derivative $\mathbf{8 q}$ has nanomolar cytotoxicity in vitro against human chronic myelogenous leukemia K562 cells. The order to further explore the possible anti-leukemia mechanism of action of $\mathbf{8 q}$ on K562 cells, a metabolomics and molecular biology study was introduced. It was thus found that most of the metabolic pathways of the G1 phase of K562 cells were affected after $\mathbf{8 q}$ treatment. The addition, a concentration-dependent accumulation of cells in the G1 phase was observed by cell cycle analysis. Western blot analysis showed that $\mathbf{8 q}$ significantly down-regulated the phosphorylation level of retinoblastoma-associated protein $(\mathrm{Rb})$ in a concentration-dependent manner, upon $48 \mathrm{~h}$ treatment. The addition, 8q induced K562 cells apoptosis, through both mitochondria-mediated and exogenous apoptotic pathways. Taken together, these results indicate that $\mathbf{8 q}$ effectively triggers G1 cell cycle arrest and induces cell apoptosis in K562 cells, by inhibiting the CDK4/6-mediated phosphorylation of Rb. Furthermore, the possible binding interactions between $\mathbf{8 q}$ and CDK4/6 protein were clarified by homology modeling and molecular docking. The order to verify the inhibitory activity of $\mathbf{8 q}$ against other chronic myeloid leukemia cells, KCL-22 cells and K562 adriamycin-resistant cells (K562/ADR) were selected for the MTT assay. It is worth noting that $\mathbf{8 q}$ showed significant anti-proliferative activity against these cell lines after $48 \mathrm{~h} / 72 \mathrm{~h}$ treatment. Therefore, this study provides new mechanistic information and guidance for the development of new acridones for application in the treatment of CML.
\end{abstract}

Keywords: metabolomics; chronic myeloid leukemia; acridone derivatives; CDK4/6; anti-leukemia mechanism

\section{Introduction}

Leukemia is a malignant clonal disease of hematopoietic stem cells that can be divided into acute and chronic types. At present, these hematological cancers are the 10th most common cause of death in the world [1]. Chronic myeloid leukemia (CML) is among the chronic leukemia types, and accounts 
for about $15-20 \%$ of all cases of leukemia in diagnosed patients [2]. The survival rate of many CML patients has been greatly improved after treatment with tyrosine kinase inhibitors such as imatinib and nilotinib. Nevertheless, the appearance of resistance can be a serious problem in the treatment of CML [3]. Therefore, it is important to develop new anticancer agents with different molecular targets or mechanisms of action for the treatment of CML. As a class of anticancer compounds, acridines and acridones have generally shown good cytotoxic or anticancer activity against acute and chronic leukemia cells [4-6]. For instance, amsacrine ( $m$-AMSA) has been used clinically in a number of countries for the treatment of acute leukemia $[7,8]$.

Among a new series of acridones synthesized previously [4], it was discovered that $\mathrm{N}-[2-$ (dimethylamino)ethyl]-1-[(3-methoxybenzyl)amino]-5-nitro-9-oxo-9,10-dihydro-acridine-4-carboxamide (8q) significantly induces mitochondrial-mediated apoptosis and targets the PI3K/AKT/FOXO1 pathway in human acute lymphoblastic leukemia CCRF-CEM cells [9]. Interestingly, it was also found that $\mathbf{8 q}$ has potent nanomolar cytotoxic activity against human chronic myelogenous leukemia K562 cells. At the same time, this molecule showed a relatively low level of toxicity based on other in vitro data. Moreover, in silico calculations showed that $\mathbf{8 q}$ conforms to Lipinski's rule of five, and is predicted to have good pharmacokinetic properties. However, the anti-chronic leukemia mechanism of action for this compound is still unclear. Metabolomics is a tool that can be used to effectively study the mechanisms of anti-cancer drugs, due to the impact of the cancer on cellular metabolism. Herein, a sensitive and accurate ultra-performance liquid chromatography/time-of-flight mass spectrometry (UPLC/Q-TOF MS) instrument was used to conduct the metabolomics profiling of chronic myelogenous leukemia K562 cells treated with the benzyl acridone analogue 8q. Furthermore, molecular biology methods, homology modeling and molecular docking strategies were employed in this study to further investigate the possible anti-leukemia mechanism for this molecule.

\section{Results}

\subsection{Multivariate Statistical Analysis and Changes in Metabolites}

Metabolomics was used to study the possible mechanism of action for $\mathbf{8 q}$ on K562 cells. The chemical structure of $\mathbf{8 q}$ is shown in Figure 1A. At first, the MTT experiment was conducted to evaluate the optimal drug concentration to use for the metabolomics study. K562 cells were treated with different concentrations of $\mathbf{8 q}(0-2.5 \mu \mathrm{M})$ for $24 \mathrm{~h}$ (Figure S1). When the concentration of $\mathbf{8 q}$ was $0.5 \mu \mathrm{M}$, the cell viability was about $80 \%$, and was deemed suitable for metabolomics research. UPLC/Q-TOF MS was used to study the changes in metabolic profiles between treated and untreated cells. As shown in Figure $1 B, C$, the respective base peak intensity (BPI) chromatograms had significant differences after $\mathbf{8 q}$ treatment in both positive and negative MS detection modes. It is noteworthy that a high concentration of $\mathbf{8 q}$ was detected in $\mathbf{8 q}$-treated cells, which indicated that $\mathbf{8 q}$ can enter the cell membrane and is not immediately metabolized. By principal component analysis (PCA, Figure 1D,E), it was shown that the metabolites of the control (DMSO) and 8q-treated group were obviously separated along the first principal component. The addition, the QC samples were tightly clustered in the middle of PCA scores, indicating the stability of the system throughout the experimental study. Therefore, these results show that the cellular metabolic phenotypes were significantly changed after treatment with $\mathbf{8 q}$. Next, the different metabolites between control and $\mathbf{8 q}$-treated group were assessed by independent $\mathrm{t}$-test and false discovery rate. The q value was found to be less than 0.05 , which indicated that there were significant differences between the two groups, and the corresponding metabolites were selected as potential biomarkers. A total of 119 significantly changed metabolites were identified in different ion modes, including 33 metabolites in the positive ion mode and 86 metabolites in the negative ion mode. Potential biomarkers were identified based on HR-MS spectra and MS/MS fragments, and compared with the corresponding standards in the database (HMDB, METLIN and lipid map). Metabolites in positive and negative ion modes are summarized in Tables 1 and 2, respectively. The results of matched MS/MS spectra metabolites have also been appended in Tables S1 and S2. 


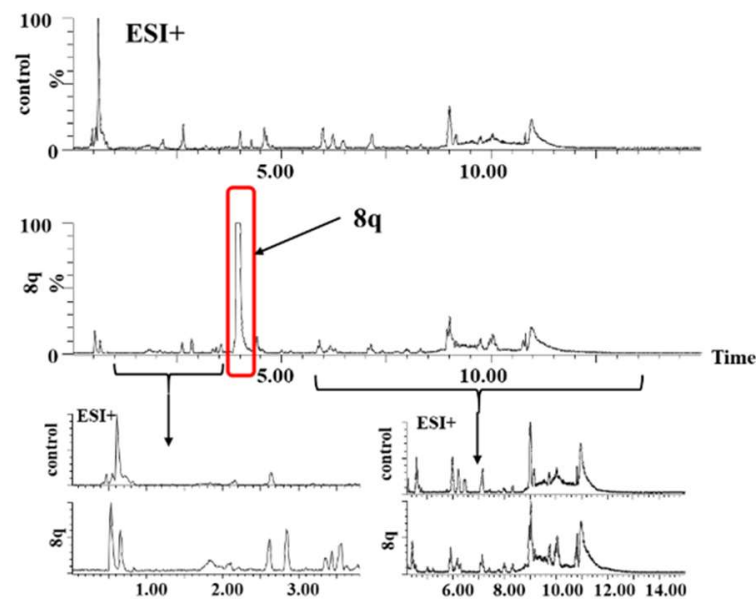

B

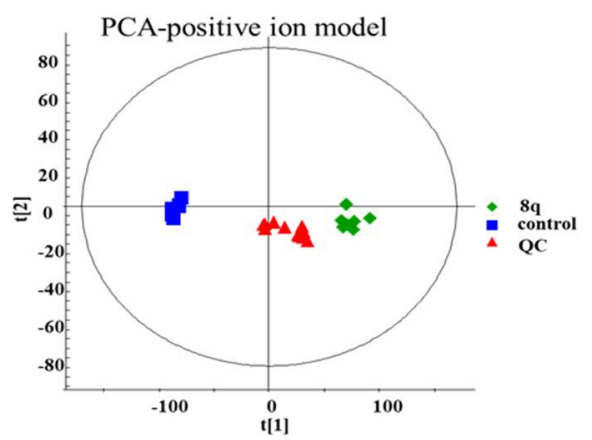

D

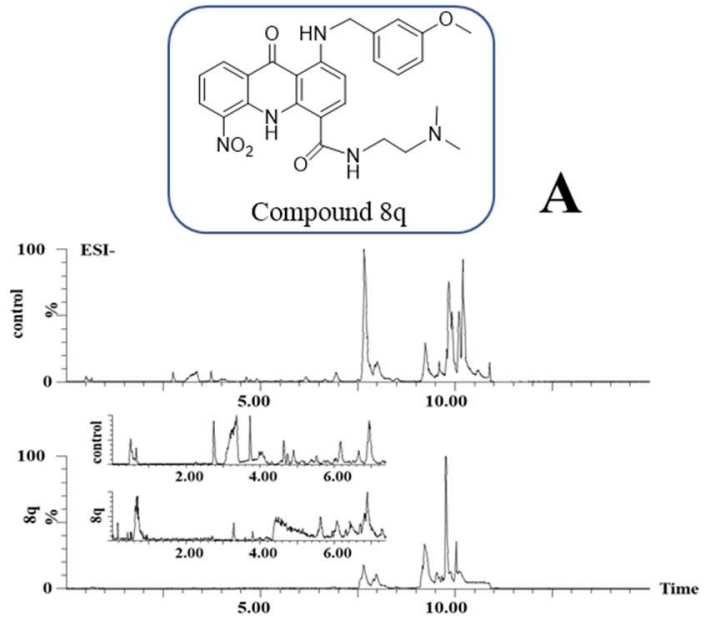

C

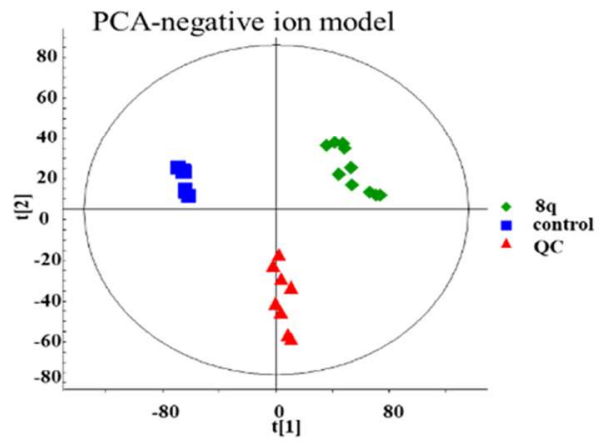

E

Figure 1. LC-MS based metabolomics study of K562 cells treated with 8q. (A) Chemical structure of 8q; (B) base peak intensity (BPI) chromatograms obtained from control and treated K562 cell extracts in positive ion mode; (C) and negative ion mode; (D) PCA of positive ion mode data; (E) PCA of negative ion mode data. 
Table 1. Summary of metabolites in positive ion mode.

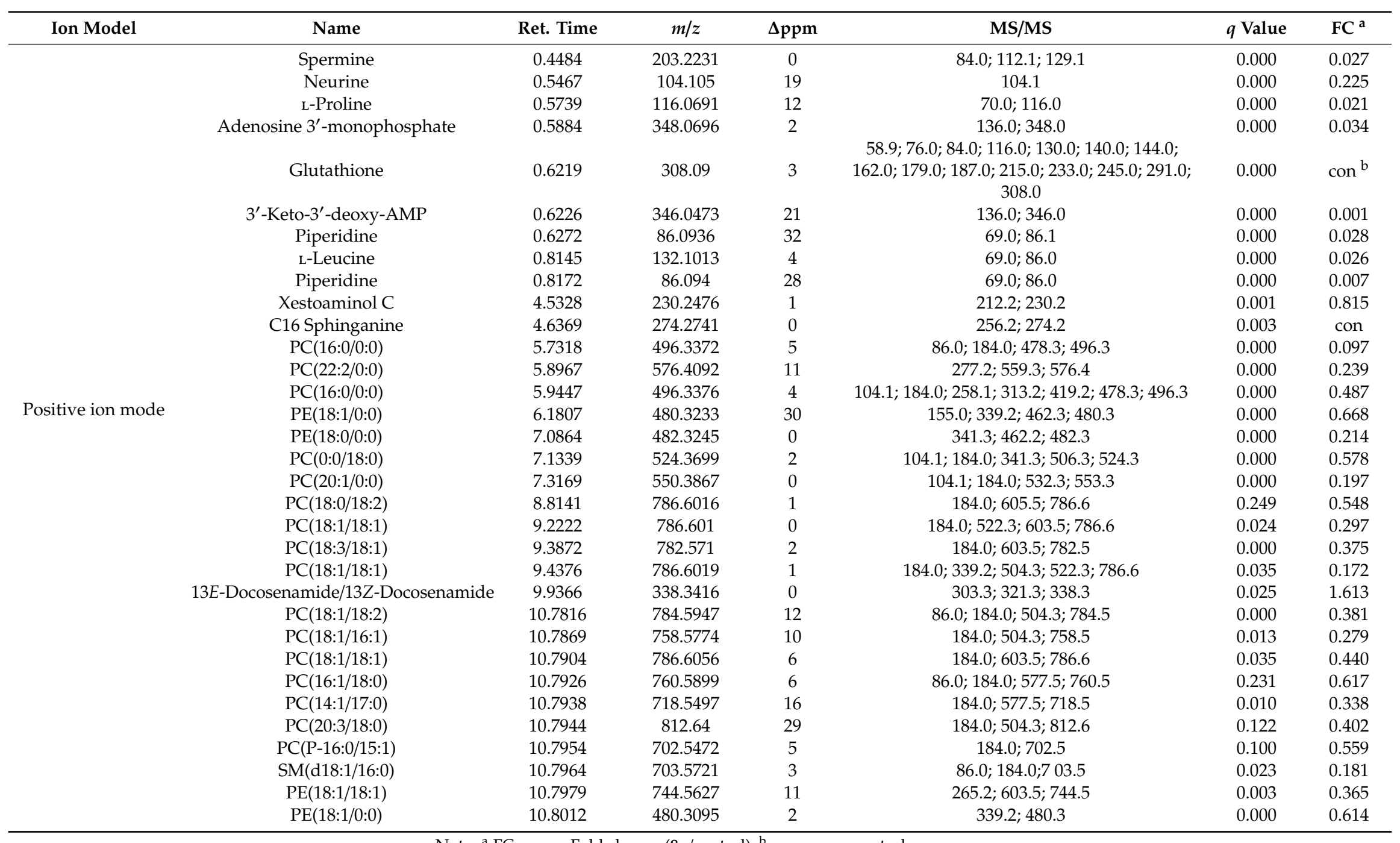

Note: ${ }^{a}$ FC means Fold change (8q/control); ${ }^{b}$ con means control group. 
Table 2. Summary of metabolites in negative ion mode.

\begin{tabular}{|c|c|c|c|c|c|c|c|}
\hline Ion Model & Name & Ret. Time & $m / z$ & $\Delta \mathrm{ppm}$ & MS/MS & $q$ Value & $\mathrm{FC}^{\mathrm{a}}$ \\
\hline \multirow{36}{*}{ Negative ion mode } & UDP-glucose/UDP-D-galactose & 0.5493 & 565.0425 & 9 & $78.9 ; 96.9 ; 241.0 ; 323.0 ; 385.0 ; 565.0$ & 0.000 & 0.002 \\
\hline & $\begin{array}{c}\text { Uridine } \\
\text { diphosphate- } N \text {-acetylglucosamine }\end{array}$ & 0.5502 & 606.0683 & 9 & $78.9 ; 158.9 ; 272.9 ; 282.0 ; 384.9 ; 403.0 ; 606.0$ & 0.000 & 0.002 \\
\hline & ADP & 0.5611 & 426.0179 & 9 & $78.9 ; 134.0 ; 158.9 ; 272.9 ; 328.0 ; 408.0 ; 426.0$ & 0.000 & 0.004 \\
\hline & Inosine $5^{\prime}$-monophosphate (IMP) & 0.5714 & 347.0376 & 6 & $78.9 ; 96.9 ; 347.0$ & 0.000 & 0.011 \\
\hline & $\begin{array}{l}\text { 5-Aminoimidazole-4-carboxamide-1- } \\
\beta \text {-D-ribofuranosyl 5'-monophosphate }\end{array}$ & 0.5799 & 337.0528 & 7 & $78.9 ; 96.9 ; 337.0$ & 0.000 & 0.007 \\
\hline & L-Aspartic Acid & 0.5844 & 132.0255 & 35 & $88.0 ; 114.0 ; 132.0$ & 0.000 & 0.009 \\
\hline & L-Glutamate & 0.5857 & 146.0426 & 22 & $102.0 ; 128.0 ; 146.0$ & 0.000 & 0.049 \\
\hline & D-Glycerol 1-phosphate & 0.5858 & 171.0083 & 11 & $78.9 ; 89.0 ; 171.0$ & 0.000 & 0.012 \\
\hline & Sulfuric acid & 0.591 & 96.9602 & 0 & $78.9 ; 96.9$ & 0.000 & 0.235 \\
\hline & Adenosine monophosphate & 0.6116 & 346.0515 & 12 & $78.9 ; 96.9 ; 211.0 ; 346.0$ & 0.000 & 0.026 \\
\hline & L-Glutamine & 0.6118 & 145.0599 & 13 & $102.0 ; 128.0 ; 146.9$ & 0.000 & 0.003 \\
\hline & L-Leucine & 0.7127 & 130.0842 & 24 & 130.0 & 0.000 & 0.077 \\
\hline & Cumanin & 4.6125 & 265.1467 & 8 & $96.9 ; 265.1$ & 0.007 & 0.143 \\
\hline & Dehydroabietic acid & 5.6388 & 299.2017 & 0 & 299.2 & 0.000 & 2.076 \\
\hline & PE(P-16:0/0:0) & 6.3388 & 436.2828 & 1 & $153.0 ; 196.0 ; 239.2 ; 436.2$ & 0.002 & 1.535 \\
\hline & Arginyl-Glutamine & 6.4253 & 301.1607 & 7 & $217.0 ; 286.1 ; 301.1$ & 0.000 & 2.691 \\
\hline & $\Delta 2$-trans-Hexadecenoic Acid & 6.4529 & 253.2172 & 0 & $84.5 ; 253.2$ & 0.012 & 2.286 \\
\hline & Arachidonic Acid (peroxide free) & 6.7046 & 303.2337 & 2 & $205.1 ; 259.2 ; 303.2$ & 0.000 & 71.665 \\
\hline & Arginyl-Gamma-glutamate & 6.8151 & 301.1606 & 7 & 301.1 & 0.000 & 2.560 \\
\hline & PE(18:0/0:0) & 7.2382 & 480.3079 & 3 & $196.0 ; 283.2 ; 480.3$ & 0.000 & 0.416 \\
\hline & Petroselinic acid/Oleic Acid & 7.9889 & 281.2483 & 1 & 281.2 & 0.000 & 3.103 \\
\hline & 11Z,14Z-Eicosadienoic Acid & 8.4771 & 307.2647 & 1 & 307.2 & 0.000 & 7.295 \\
\hline & Stearic acid & 9.222 & 283.2654 & 4 & $265.3 ; 283.2$ & 0.000 & 2.336 \\
\hline & $\operatorname{PI}(20: 5 / 18: 1)$ & 9.3598 & 881.5158 & 3 & $241.0 ; 281.2 ; 881.5$ & 0.000 & 2.836 \\
\hline & $\begin{array}{l}\text { cis-gondoic acid/ } \\
2 E \text {-Eicosenoic acid }\end{array}$ & 9.3917 & 309.2805 & 1 & 309.2 & 0.000 & 5.116 \\
\hline & PS(18:0/19:1) & 9.4136 & 802.5604 & 0 & $283.2 ; 419.2 ; 701.5 ; 802.5$ & 0.005 & 0.751 \\
\hline & PS(18:0/18:1) & 9.4246 & 788.5407 & 5 & $152.9 ; 283.2 ; 419.2 ; 701.5 ; 788.5$ & 0.001 & 0.545 \\
\hline & PG(18:1/22:6) & 9.4363 & 819.525 & 8 & $281.2 ; 327.2 ; 419.2 ; 819.5$ & 0.000 & 0.516 \\
\hline & $\operatorname{PI}(20: 4 / 16: 0)$ & 9.5244 & 857.5121 & 7 & $241.0 ; 303.2 ; 391.2 ; 553.2 ; 857.5$ & 0.000 & 3.782 \\
\hline & $\operatorname{PI}(20: 4 / 18: 1)$ & 9.5572 & 883.5157 & 20 & $152.9 ; 222.9 ; 241.0 ; 303.2 ; 417.2 ; 579.2 ; 883.5$ & 0.001 & 1.449 \\
\hline & PG(18:3/18:1) & 9.5579 & 769.5007 & 2 & $152.9 ; 277.2 ; 281.2 ; 769.5$ & 0.000 & 11.712 \\
\hline & PI(16:1/18:1) & 9.5732 & 833.5135 & 6 & $152.9 ; 241.0 ; 253.2 ; 281.2 ; 389.2 ; 417.2 ; 579.2 ; 833.5$ & 0.000 & 0.752 \\
\hline & PG(20:3/18:1) & 9.6053 & 797.53 & 4 & $152.9 ; 281.2 ; 305.2 ; 765.6 ; 797.5$ & 0.000 & 0.330 \\
\hline & PS(18:0/18:1) & 9.6188 & 788.5404 & 5 & $152.9 ; 281.2 ; 283.2 ; 417.2 ; 419.2 ; 701.5 ; 788.5$ & 0.000 & 0.086 \\
\hline & PG(18:1/20:4) & 9.6202 & 795.5092 & 11 & $281.2 ; 303.2 ; 417.2 ; 795.5$ & 0.000 & 16.215 \\
\hline & $\operatorname{PI}(18: 1 / 18: 2)$ & 9.6278 & 859.5297 & 5 & $152.9 ; 241.0 ; 279 / 2 ; 281.2 ; 415.2 ; 417.2 ; 577.2 ; 579.2 ; 859.5$ & 0.007 & 1.146 \\
\hline
\end{tabular}


Table 2. Cont

\begin{tabular}{|c|c|c|c|c|c|c|c|}
\hline Ion Model & Name & Ret. Time & $m / z$ & $\Delta$ ppm & MS/MS & $q$ Value & $\mathrm{FC}^{\mathrm{a}}$ \\
\hline & 7,7-dimethyl-5,8-Eicosadienoic Acid & 9.6238 & 335.2971 & 4 & 335.2 & 0.000 & 5.874 \\
\hline & PG(16:1/18:1) & 9.6489 & 745.4967 & 7 & $152.9 ; 253.2 ; 281.2 ; 389.2 ; 491.2 ; 673.5 ; 745.4$ & 0.000 & 17.477 \\
\hline & $\operatorname{PI}(20: 2 / 20: 4)$ & 9.659 & 909.5474 & 2 & $241.0 ; 303.2 ; 307.2 ; 439.2 ; 443.2 ; 909.5$ & 0.000 & 1.953 \\
\hline & Nervonic acid & 9.6611 & 365.3426 & 0 & 365.3 & 0.000 & 3.921 \\
\hline & PG(18:2/18:1) & 9.6761 & 771.5117 & 8 & $152.9 ; 279.2 ; 281.2 ; 771.5$ & 0.000 & 4.204 \\
\hline & Docosanoic acid & 9.7185 & 339.3293 & 7 & 339.3 & 0.000 & 3.146 \\
\hline & PG(18:1/17:1) & 9.7688 & 759.5153 & 3 & $152.9 ; 267.2 ; 281.2 ; 759.5$ & 0.000 & 8.753 \\
\hline & $\operatorname{PI}(20: 4 / 18: 0)$ & 9.7744 & 885.546 & 4 & $223.0 ; 241.0 ; 283.2 ; 303.2 ; 419.2 ; 581.3 ; 885.5$ & 0.000 & 2.928 \\
\hline & PI(18:0/22:5) & 9.7767 & 911.5626 & 3 & $152.9 ; 241.0 ; 329.2 ; 419.2 ; 581.3 ; 607.3 ; 911.5$ & 0.000 & 1.520 \\
\hline & $\operatorname{PG}(18: 1 / 15: 0)$ & 9.7803 & 733.4986 & 5 & $281.2 ; 733.4$ & 0.000 & 3.943 \\
\hline & $\mathrm{PI}(\mathrm{O}-16: 0 / 18: 1)$ & 9.8087 & 821.5381 & 20 & $255.2 ; 281.2 ; 437.2 ; 745.5 ; 821.5$ & 0.018 & 1.521 \\
\hline & $\mathrm{PA}(17: 0 / 16: 1)$ & 9.8117 & 659.4584 & 11 & $253.2 ; 659.4$ & 0.000 & 6.842 \\
\hline & $\operatorname{PI}(18: 1 / 18: 1)$ & 9.8177 & 861.5442 & 6 & $78.9 ; 223.0 ; 241.0 ; 281.2 ; 417.2 ; 579.2 ; 792.5 ; 861.5$ & 0.007 & 0.677 \\
\hline & $\operatorname{PG}(18: 1 / 18: 1)$ & 9.833 & 773.5242 & 12 & $152.9 ; 241.2 ; 417.2 ; 509.2 ; 773.5$ & 0.031 & 1.315 \\
\hline & PG(20:2/18:1) & 9.84 & 799.5471 & 2 & $152.9 ; 281.2 ; 307.2 ; 799.5$ & 0.000 & 0.177 \\
\hline & PG(20:4/18:0) & 9.8432 & 797.5334 & 0 & $152.9 ; 260.2 ; 283.2 ; 303.2 ; 419.2 ; 511.3 ; 797.5$ & 0.000 & 51.407 \\
\hline & 5,9-hexacosadienoic acid & 9.8475 & 391.3566 & 3 & 391.3 & 0.001 & 2.517 \\
\hline & $\operatorname{PI}(18: 1 / 20: 2)$ & 9.8834 & 887.5579 & 8 & $152.9 ; 223.0 ; 241.0 ; 307.2 ; 417.2 ; 443.2 ; 579.2 ; 887.5$ & 0.000 & 0.308 \\
\hline & PG(16:0/18:1) & 9.8925 & 747.5105 & 10 & $255.2 ; 281.2 ; 465.2 ; 747.5$ & 0.000 & 0.437 \\
\hline & $\operatorname{PI}(18: 1 / 17: 0)$ & 9.9228 & 849.5507 & 0 & $241.0 ; 281.2 ; 419.2 ; 567.3 ; 849.5$ & 0.001 & 1.593 \\
\hline & $\operatorname{PI}(22: 4 / 18: 0)$ & 9.9428 & 913.5793 & 2 & $152.9 ; 283.2 ; 331.2 ; 419.2 ; 443.2 ; 581.3 ; 605.3 ; 913.5$ & 0.013 & 1.158 \\
\hline & PG(18:1/20:1) & 9.9942 & 801.5621 & 3 & $152.9 ; 281.2 ; 309.2 ; 728.5 ; 801.5$ & 0.000 & 0.162 \\
\hline & PG(22:2/18:1) & 9.9951 & 827.5801 & 0 & $281.2 ; 335.2 ; 419.2 ; 827.5$ & 0.000 & 0.057 \\
\hline & $\operatorname{PI}(18: 0 / 18: 1)$ & 10.0446 & 863.5568 & 10 & $152.9 ; 241.0 ; 281.2 ; 283.2 ; 417.2 ; 419.2 ; 581.3 ; 863.5$ & 0.027 & 0.733 \\
\hline & Lignoceric acid & 10.0555 & 367.3588 & 1 & 367.3 & 0.000 & 7.465 \\
\hline & PA(18:1/17:0) & 10.0864 & 687.4864 & 15 & $152.9 ; 281.2 ; 423.2 ; 687.4$ & 0.000 & 10.392 \\
\hline & $\mathrm{PA}(19: 1 / 18: 1)$ & 10.0979 & 713.4849 & 38 & $152.9 ; 253.2 ; 281.2 ; 417.2 ; 713.4$ & 0.000 & 4.158 \\
\hline & $\operatorname{PI}(22: 2 / 18: 1)$ & 10.1148 & 915.599 & 2 & $152.9 ; 241.0 ; 417.2 ; 579.2 ; 915.5$ & 0.000 & 0.475 \\
\hline & $\operatorname{PI}(20: 2 / 18: 0)$ & 10.1387 & 889.5771 & 4 & $223.0 ; 241.0 ; 283.2 ; 307.2 ; 419.2 ; 443.2 ; 581.3 ; 599.3$ & 0.000 & 0.380 \\
\hline & PG(18:0/18:1) & 10.1847 & 775.5441 & 6 & $152.9 ; 281.2 ; 283.2 ; 419.2 ; 493.2 ; 511.3 ; 775.5$ & 0.001 & 0.789 \\
\hline & PE(P-18:1/18:3) & 10.2445 & 722.5086 & 6 & $152.9 ; 281.2 ; 413.1 ; 417.2 ; 722.5$ & 0.002 & 0.404 \\
\hline & $\operatorname{PI}(22: 2 / 20: 1)$ & 10.4522 & 943.6288 & 0 & $241.0 ; 445.2 ; 607.3$ & 0.000 & 0.303 \\
\hline & $\operatorname{PS}(18: 0 / 18: 1)$ & 10.5039 & 788.5415 & 4 & $152.9 ; 281.2 ; 283.2 ; 417.2 ; 419.2 ; 701.5 ; 788.5$ & 0.020 & 0.212 \\
\hline & PI(18:0/20:1) & 10.5194 & 891.5939 & 3 & $153.0 ; 223.0 ; 241.0 ; 283.2 ; 309.2 ; 419.2 ; 581.3 ; 891.5$ & 0.003 & 0.020 \\
\hline & $\operatorname{PI}(22: 2 / 18: 0)$ & 10.5319 & 917.6085 & 4 & 153.0; 223.0; 241.0; 335.2; 419.2; 581.3; 917.6 & 0.000 & 0.613 \\
\hline
\end{tabular}


Table 2. Cont.

\begin{tabular}{|c|c|c|c|c|c|c|c|}
\hline Ion Model & Name & Ret. Time & $m / z$ & $\Delta \mathrm{ppm}$ & MS/MS & $q$ Value & $\mathrm{FC}^{\mathrm{a}}$ \\
\hline & Arachidic Acid/Phytanic Acid & 10.5858 & 311.2971 & 4 & 311.2 & 0.000 & 2.173 \\
\hline & 13Z-Docosenoic Acid & 10.6089 & 337.3124 & 3 & 337.3 & 0.000 & 2.192 \\
\hline & Oleic Acid & 10.8021 & 281.2501 & 5 & 281.2 & 0.001 & 1.746 \\
\hline & $\operatorname{PA}(20: 2 / 18: 1)$ & 10.8195 & 725.4859 & 36 & $152.9 ; 281.2 ; 417.2 ; 462.3$ & 0.011 & 0.607 \\
\hline & PE(18:1/18:1) & 10.8206 & 742.5396 & 0 & $196.0 ; 281.2 ; 460.2 ; 478.2 ; 742.5$ & 0.003 & 0.334 \\
\hline & PI(20:2/18:0) & 10.8474 & 889.5809 & 2 & $241.0 ; 283.2 ; 307.2 ; 889.5$ & 0.008 & 0.570 \\
\hline & PS(22:1/18:1 & 10.8657 & 842.5978 & 7 & $281.2 ; 755.5 ; 842.5$ & 0.000 & 0.147 \\
\hline & PS(18:0/19:1 & 10.8682 & 802.5587 & 2 & $152.9 ; 281.2 ; 419.2 ; 710.5 ; 715.2 ; 802.5$ & 0.000 & 0.420 \\
\hline & $\operatorname{PS}(18: 0 / 18: 1)$ & 10.8685 & 788.5394 & 6 & $152.9 ; 283.2 ; 419.2 ; 701.5 ; 788.5$ & 0.000 & 0.365 \\
\hline & PS(18:1/18:1) & 10.8723 & 786.5269 & 2 & $152.9 ; 281.2 ; 417.2 ; 699.4 ; 701.5 ; 786.5$ & 0.000 & 0.240 \\
\hline & $\operatorname{PS}(18: 0 / 22: 6)$ & 10.8727 & 834.5257 & 3 & $283.2 ; 419.2 ; 463.2 ; 747.4 ; 834.5$ & 0.000 & 0.350 \\
\hline & PS(18:1/16:0) & 10.8735 & 760.5147 & 1 & $152.9 ; 255.2 ; 281.2 ; 391.2 ; 673.5$ & 0.000 & 0.109 \\
\hline & PI(20:4/18:0) & 10.8741 & 885.55 & 0 & $241.0 ; 419.2 ; 581.3 ; 885.5$ & 0.000 & 2.550 \\
\hline & PG(18:0/17:1) & 10.8803 & 761.5346 & 1 & $152.9 ; 283.2 ; 391.2 ; 419.2 ; 687.5 ; 761.5$ & 0.001 & 0.086 \\
\hline
\end{tabular}

Note: ${ }^{\text {a }}$ FC means Fold change (8q/control). 


\subsection{Metabolic Pathway Analysis}

Changes in metabolic pathways caused by $\mathbf{8 q}$-treated cells were analyzed by the available online tools Biochemical Pathways (http://biochemical-pathways.com) and MetaboAnalyst 3.0 (http: //www.metaboanalyst.ca). As shown in Figure 2A,B, the metabolic pathways disturbed by $\mathbf{8 q}$ mainly included purine metabolism, alanine, aspartate and glutamate metabolism, arginine and proline metabolism, glycerophospholipid metabolism, D-glutamine and D-glutamate, aminoacyl-tRNA biosynthesis and glutathione metabolism. Purines supply the essential synthesis substrates for DNA and RNA [10], and purine metabolism is often abnormally increased in tumor cells for rapid growth and proliferation that mainly affects the G1 phase of the cell cycle [11]. Amino acids are essential for the synthesis of proteins and aminoacyl tRNA that are also especially important in the G1 phase [12,13]. The metabolites here detected in five amino acid (alanine, aspartate, glutamate, arginine, and proline) metabolic pathways are also involved in aminoacyl-tRNA biosynthesis [14]. As shown in Tables S1 and S2, it was observed that the concentrations of L-glutamine, L-aspartate, L-leucine, L-proline and L-glutamate were all decreased after $\mathbf{8 q}$ treatment. Hence, it was speculated that aminoacyl-tRNA biosynthesis was inhibited. Aminoacyl-tRNA biosynthesis is occurring at the G1 phase, as catalyzed by tRNA synthase [15]. When tRNA synthase is inhibited, the aminoacyl-tRNA biosynthesis is blocked and cells will arrest in the G1 phase. Therefore, flow cytometry analysis can be used for further investigating the effect of $\mathbf{8 q}$ on the cell cycle based on the above results.

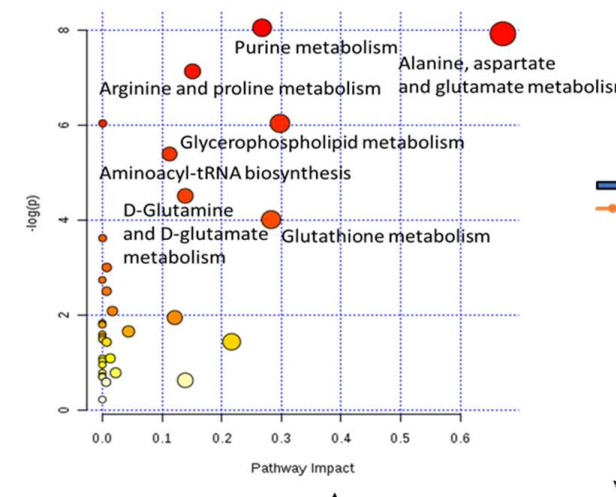

A

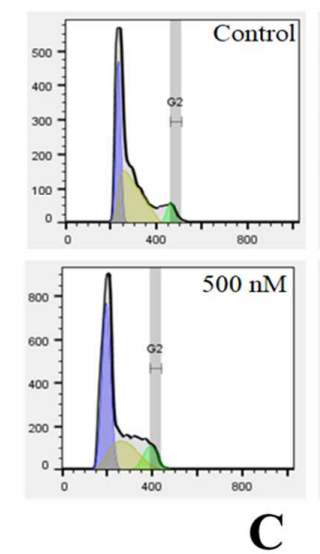

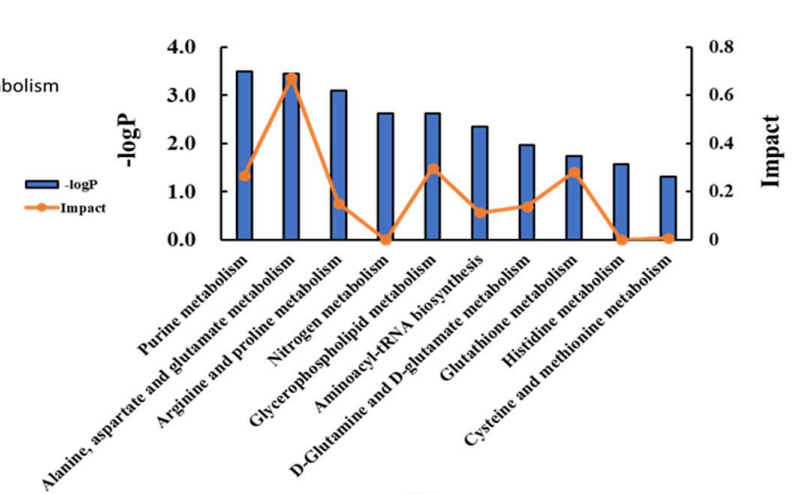

B

Figure 2. (A) Metabolic pathways altered by cell treatment with 8q. (B) Quantitative analysis of the impact of $\mathbf{8 q}$ on metabolic pathways. (C) Flow cytometric analysis of $\mathbf{8 q}$ induction of G0/G1 phase cell cycle arrest in K562 cells. K562 cells were treated with 8q at the indicated concentrations for $48 \mathrm{~h}$. (D) Cell cycle phase analysis of K562 cells treated with 8q. 


\subsection{8q Effectively Triggered G1 Cell Cycle Arrest in K562 Cells}

After the treatment of K562 cells with $8 \mathrm{q}$ at $200 \mathrm{nM}, 500 \mathrm{nM}$ and $800 \mathrm{nM}$ for $48 \mathrm{~h}$, the cells were found to be arrested in the G1 phase of the cell cycle in a concentration-dependent manner. As shown in Figure 2C,D, the cell population in G0/G1 increased from 37.7\% in untreated cells to $45.4 \%, 56.6 \%$ and $65.8 \%$ in the cells treated with $8 \mathbf{q}$ at $200 \mathrm{nM}, 500 \mathrm{nM}$ and $800 \mathrm{nM}$, respectively. That is, the data show that treatment with $\mathbf{8 q}$ results in G1 cell cycle arrest in K562 cells.

\section{4. $8 q$ Showed Concentration-Dependent Inhibition of the Phosphorylation of the CDK4/6 Substrate Rb}

CDK4/6 is a specific protein of the G1 phase that binds with cyclin D to form a complex, promotes phosphorylation of target retinoblastoma-associated protein $(\mathrm{Rb})$, and then allows the cell cycle to enter the S phase [16]. The phosphorylation of $\mathrm{Rb}$ is required for the G1-S transition of the cell cycle. Therefore, selective inhibition of $\mathrm{Rb}$ phosphorylation can cause the arrest of the cell cycle in $\mathrm{G} 1$ phase. As shown in Western blots (Figure 3A,B), 8q (200-800 nM) significantly inhibits CDK 4/6-mediated phosphorylation of $\mathrm{Rb}$, and the expression of $\mathrm{Rb}$ protein increased slightly, in a concentration-dependent manner. The addition, the level of cyclin D1 in K562 cells also decreased in a concentration-dependent manner, upon $48 \mathrm{~h}$ treatment with 8q. Meanwhile, the level of CDK4 was found to increase dramatically. It may be that $\mathbf{8 q}$ affects the formation of CDK4 and cyclin D1 complexes, which is the key step to regulate $\mathrm{Rb}[17,18]$. Accordingly, based on the results of the Western blotting and cell cycle analysis, it is suggested that 8q effectively triggers G1 cell cycle arrest in K562 cells by inhibiting $\mathrm{CDK} 4 / 6$-mediated phosphorylation of $\mathrm{Rb}$.
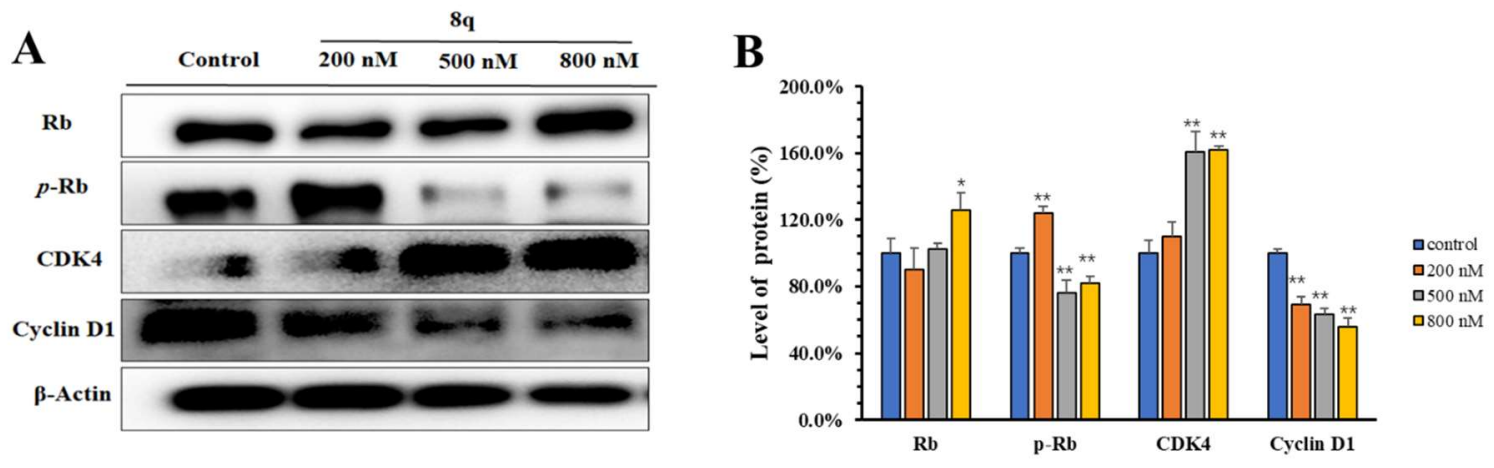

Figure 3. (A) 8q inhibited CDK 4/6-mediated phosphorylation of $\mathrm{Rb}$; (B) The densitometry of proteins performed on the Western blotting of $\mathrm{A},{ }^{*} p<0.05 ;{ }^{* *} p<0.01$.

\subsection{Homology Modeling of CDK4/6 Protein and Molecular Docking}

CDK4/6 inhibitors inhibit the progression of cancer cells from G1 to S phase and trigger G1 cell cycle arrest by selectively inhibiting the function of CDK4/6 [19]. After metabolomics and molecular biology studies performed here revealed that the benzyl acridone $\mathbf{8 q}$ might be a CDK4/6 inhibitor that down-regulates the phosphorylation level of downstream protein $\mathrm{Rb}$, further studies were designed to evaluate this hypothesis. Therefore, the binding interactions between $\mathbf{8 q}$ and CDK4/6 were analyzed in silico by homology modeling and molecular docking. Some CDK4 X-ray crystal structures have been obtained and reported, but all of them are in an inactive state in which the activation loop flaps over and partially closes the active site. CDK6 is a homologous protein of CDK4 with a high percentage of residue identity $(71.3 \%)$ and similar physiological function. Homology modeling was used to build an active CDK4 structure (Figure S2) according to a reported active CDK6 crystal structure (PDB ID: 2EUF). When docked in the model system, $\mathbf{8 q}$ formed several hydrogen $(\mathrm{H})$ bonds with CDK4. It had two $\mathrm{H}$ bonds with Val96 in the hinge region, which are conserved $\mathrm{H}$ bonds among known CDK4 inhibitors. The nitro group also formed one $\mathrm{H}$ bond with Asp158, the methoxy oxygen atom formed one $\mathrm{H}$ bond with Lys22, and the $\mathrm{N}, \mathrm{N}$-dimethylethylenediamine group formed another two $\mathrm{H}$ bonds 
with Glu144 and Asn145 (Figure 4A). The planar acridone ring was inserted into the active site, with its $\mathrm{N}, \mathrm{N}$-dimethylethylenediamine group extending to the negatively charged surface of CDK4 (Figure $4 \mathrm{~B}$ ). The docking result showed that $\mathbf{8 q}$ is predicted to have a good complementary interaction with CDK4.

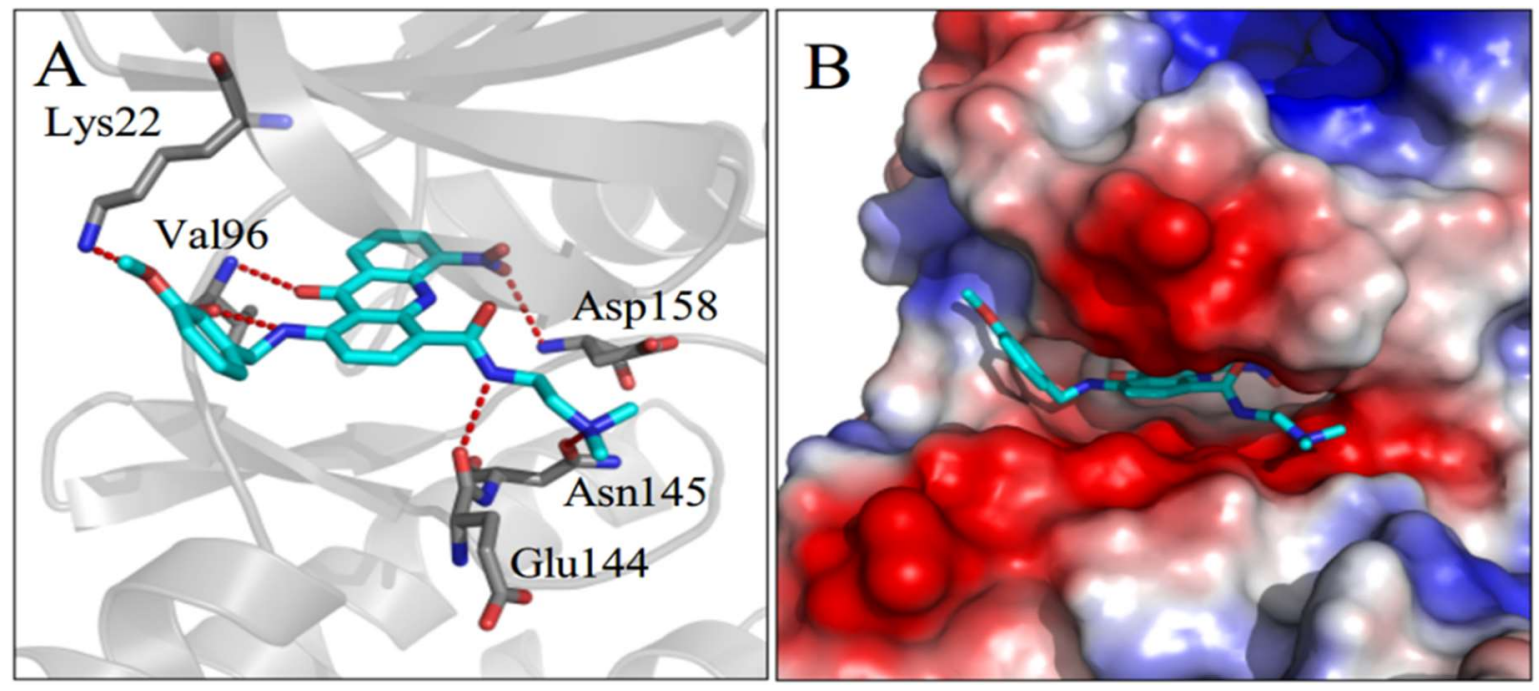

Figure 4. (A) CDK4 is depicted in grey cartoon form with grey stick residues involved in hydrogen bonding, and $\mathbf{8 q}$ is shown as a cyan stick model. Oxygen atoms and nitrogen atoms are depicted in red and blue, respectively. Hydrogen bonds are shown as red dashed lines. (B) CDK4 is represented in electrostatic surface form, with blue and red indicating positive and negative charges respectively.

\subsection{8q Significantly Induced Apoptosis in K562 Cells}

The work previously reported showed that $\mathbf{8 q}$ has a strong antiproliferative activity that was expected to lead to apoptosis, as shown in vitro using K562 cells [9]. The order to evaluate this hypothesis, a flow cytometry assay (Annexin V-FITC/PI) was conducted in K562 cells, as shown in Figure 5. The upper right-hand quadrants (Q2) showed the late stage of apoptotic or necrotic cells. The lower right-hand quadrants (Q3) showed the early stage of apoptotic cells. K562 cells were treated with $\mathbf{8 q}$ at the concentrations of $0,200,500$ and $800 \mathrm{nM}$ for $48 \mathrm{~h}$. As the concentration of $\mathbf{8 q}$ increased, the percentage of apoptotic cells increased from $6.49 \%$ to $41.90 \%$. The addition, an Annexin V-FITC/PI kit assay was conducted in K562 cells, as shown in Figure S3. Annexin V-FITC can recognize early apoptotic cells and show green fluorescence. Propidium iodide (PI) was used to identify late apoptotic and necrotic cells, showing red fluorescence. The K562 cells were treated with 8q, at concentrations of 0, 200, 500 and $800 \mathrm{nM}$ for $48 \mathrm{~h}$. Dimethyl sulfoxide (DMSO) was used as the negative treatment control. As the concentration of $\mathbf{8 q}$ was incremented, the number of early apoptotic cells increased significantly. The early apoptosis of K562 cells was detected, starting at $200 \mathrm{nM}$ of $\mathbf{8 q}$, the lowest concentration tested. When the concentration of $\mathbf{8 q}$ was $800 \mathrm{nM}$, the number of late apoptotic cells also increased significantly. Additionally, the number of late apoptotic cells and necrotic cells also increased in a concentration-dependent manner. However, the trend of late apoptotic and necrotic cells was not as obvious as compared with that of early apoptotic cells. Therefore, it was concluded that 8q effectively induces K562 cells apoptosis in a concentration-dependent manner. However, the late apoptosis and necrosis induced by $\mathbf{8 q}$ could not be well distinguished in this test. Therefore, apoptosis and necrosis analyses were carried out using Hoechst 33342/PI kit. Similarly, it was confirmed that 8q significantly induces apoptosis in K562 cells from the results shown in Figure S4. Hoechst 33342 (purchased from Beyotime Biotechnology, Shanghai, China) can be used to recognize apoptotic cells (blue fluorescence), and PI is used to identify necrotic cells (red fluorescence). Taking the above into consideration, the results suggested that $\mathbf{8 q}$ induces apoptosis and inhibits the proliferation of K562 cells. 

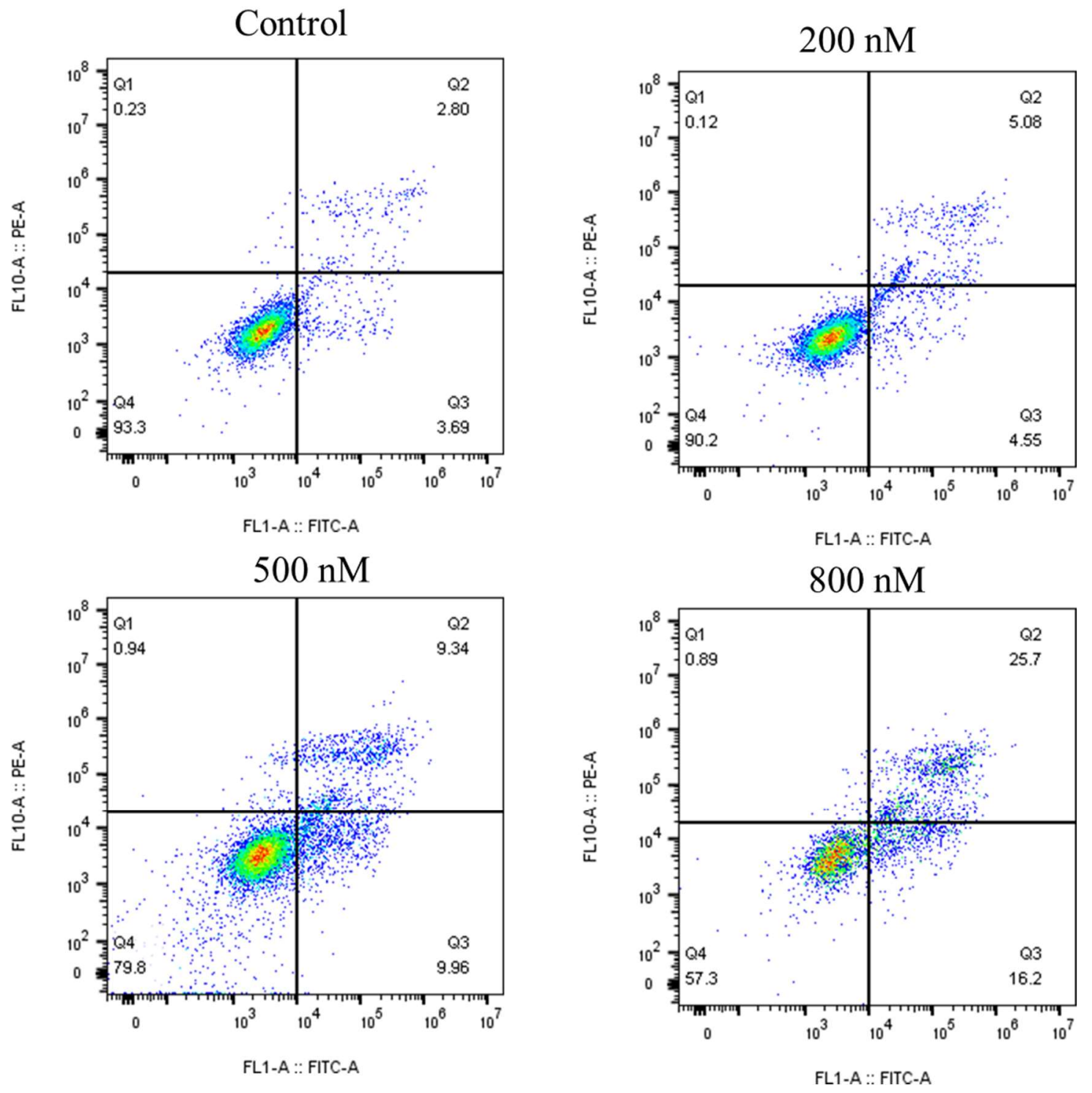

Figure 5. 8q induced apoptosis in K562 cells (48 h) at different concentrations (0, 200, 500, $800 \mathrm{nM})$. DMSO as a negative control.

\subsection{8q Induced Apoptosis through the Caspase Pathway}

Apoptotic pathways are divided into mitochondria-mediated (intrinsic) and exogenous apoptotic pathways [20]. Caspase family proteins, such as Caspase-9, 8 and 3, are the main executors of apoptosis, and the activity changes of different caspase isoforms can distinguish the apoptosis pathways [21,22]. From the results (Figure $6 \mathrm{~A}, \mathrm{~B}$ ), we can see that $\mathbf{8 q}$ activated Caspase- 9,8 and 3 proteins in a concentration-dependent manner. These results suggested that 8q induced K562 cells apoptosis through both mitochondria-mediated and exogenous apoptotic pathways. Z-VAD-FMK is a pan-caspase inhibitor. When K562 cells were pretreated with Z-VAD-FMK $(10 \mu \mathrm{M}), \mathbf{8 q}(800 \mathrm{nM})$ could not induce the up-regulation of cleaved Caspase-3 when compared with those without Z-VAD-FMK pretreatment (Figure 6C,D). Therefore, these results demonstrate that apoptosis is the main cell death mechanism upon 8q treatment in K562 cells. 
A

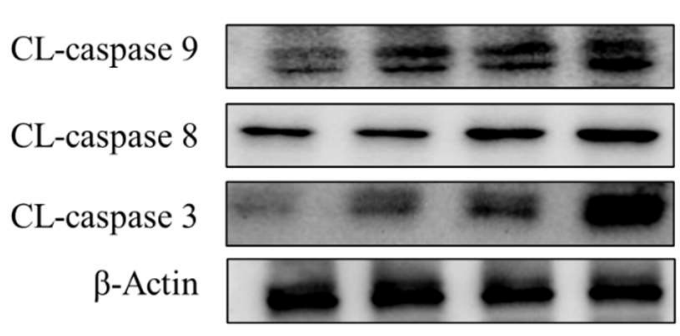

C

CL-Caspase 3

$\beta$-Actin
Control $200 \mathrm{nM} 500 \mathrm{nM} 800 \mathrm{nM}$
B

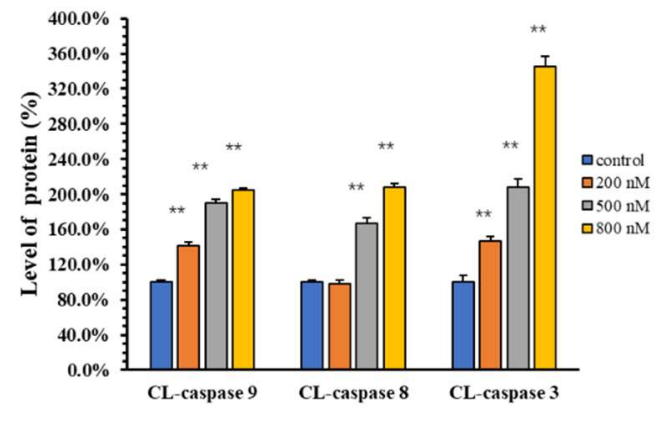

D

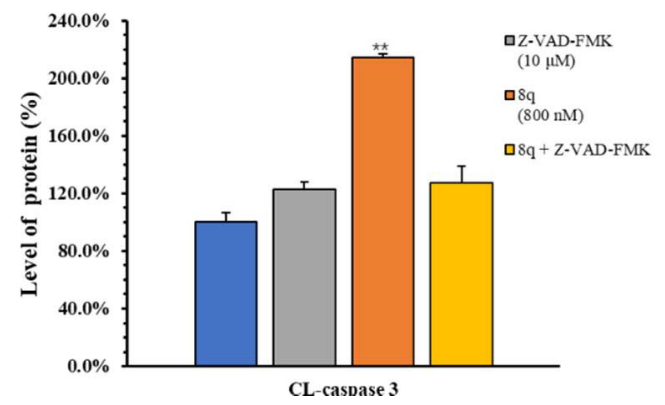

Figure 6. 8q induced both mitochondria-mediated and exogenous apoptosis. (A) The expressions of caspase family proteins were determined after $\mathbf{8 q}$ treatment; (B) The densitometry of caspase family proteins performed on the Western blotting of $A,{ }^{* *} p<0.01$; (C) The expressions of caspase- 3 were determined after $8 \mathbf{q}(800 \mathrm{nM})$ or Z-VAD-FMK $(10 \mu \mathrm{M})$ treatment; (D) The densitometry of caspase-3 performed on the western blotting of $C, * * p<0.01$.

\subsection{The Vitro Anti-Proliferation Activity of KCL-22 and K562/ADR Cells}

The order to verify the inhibitory activity of compound $\mathbf{8 q}$ on other chronic myeloid leukemia cells, we selected KCL-22 cells for the MTT assay. The addition, human leukemia K562 adriamycin-resistant cells (K562/ADR) were also selected in the assay, to investigate whether $\mathbf{8 q}$ had in vitro anti-proliferative activity against drug-resistant cell line. The results were shown in Figure 7. It is worth noting that 8q showed obvious anti-proliferative activity against KCL-22 cells and K562/ADR cells, with $\mathrm{IC}_{50}$ values of $520 \mathrm{nM}$ and $250 \mathrm{nM}$ after $48 \mathrm{~h}$ treatment. The addition, when these cell lines were treated with $\mathbf{8 q}$ for $72 \mathrm{~h}$, we found that the inhibitory activity was significantly increased, and the $\mathrm{IC}_{50}$ values were $90 \mathrm{nM}$ and $170 \mathrm{nM}$, respectively. Therefore, it is suggested that compound $\mathbf{8 q}$ not only had good in vitro anti-proliferative activity against other CML cells, but also had significant inhibitory activity against drug-resistant leukemia cells. Thus, $\mathbf{8 q}$ may be a promising hit compound in the treatment of CML.

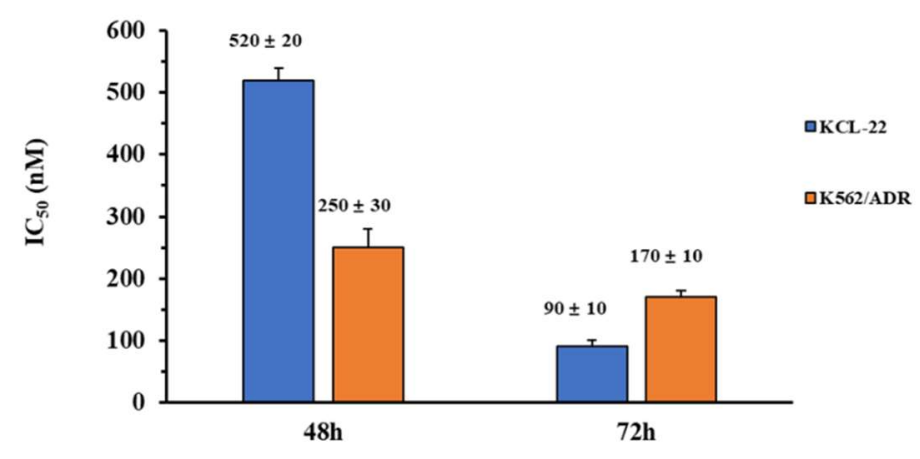

Figure 7. Antiproliferative activity of $\mathbf{8 q}$ against KCL-22 and K562-ADR cells. 


\section{Discussion}

Our previous work reported that the new methoxybenzyl 5-nitroacridone 8q exhibits strong anti-proliferation activity against human chronic myelogenous leukemia K562 cells and had relatively low toxicity in vitro. The this study, through the analysis of metabolic principal components and metabolic pathways, it was found that $\mathbf{8 q}$ induced significant changes in the metabolites of K562 cells, and that most of the metabolic pathways affected the G1 phase of cancer cells, such as purine metabolism, aminoacyl-tRNA biosynthesis, and so on. The addition, a concentration-dependent accumulation of cells in G1 phase was observed by cell cycle analysis after treatment with $\mathbf{8 q}$. CDK4/6 is a specific protein of the G1 phase that binds with cyclin D to form a complex, promotes the phosphorylation of target $\mathrm{Rb}$ protein, and then allows the cell cycle to enter the $\mathrm{S}$ phase. Therefore, the phosphorylation of $\mathrm{Rb}$ is required for the G1-S transition of the cell cycle. Western blot analysis showed that the expression levels of phosphorylated $\mathrm{Rb}$ and cyclin $\mathrm{D} 1$ significantly decreased in a concentration dependent manner after $\mathbf{8 q}$ treatment for $48 \mathrm{~h}$, in addition, $\mathbf{8 q}$ obviously increased the expression level of CDK4 in K562 cells with the increase of the drug's concentration. Furthermore, the likely binding interactions between $\mathbf{8 q}$ and CDK4/6 were clarified by in silico molecular docking studies. Therefore, these results suggest that $\mathbf{8 q}$ can effectively trigger G1 cell cycle arrest in K562 cells by inhibiting CDK4/6-mediated phosphorylation of Rb.

Cell cycle arrest is often associated with cell apoptosis. This study continued to investigate whether 8q can induce K562 cells apoptosis and further verify which apoptotic pathway it followed. Apoptosis and necrosis detection assay showed that the percentage of apoptotic cells increased from $6.49 \%$ to $41.90 \%$ as the concentration of $\mathbf{8 q}$ increased. It is suggested that $\mathbf{8 q}$ significantly induces cell apoptosis and inhibits the proliferation of K562 cells. Western blotting results further displayed that $8 \mathbf{q}$ induced K562 cells apoptosis through both mitochondria-mediated and exogenous apoptotic pathways. The addition, we observed that, after pretreating K562 cells with Z-VAD-FMK (a pan-caspase inhibitor), the effect of $\mathbf{8 q}$ on the cleavage of Caspase-3 disappeared, suggesting that $\mathbf{8 q}$ induced apoptosis through the caspase pathway. Furthermore, the MTT assay showed that $\mathbf{8 q}$ not only had good in vitro anti-proliferative activity against other CML cells (KCL-22 cells), but also had significant inhibitory activity against drug-resistant leukemia cells (K562/ADR cells).

The conclusion, the reported results suggest that $\mathbf{8 q}$ can effectively trigger $\mathrm{G} 1$ cell cycle arrest and induce cell apoptosis in K562 cells by inhibiting CDK4/6-mediated phosphorylation of Rb. This study accordingly provides new information and guidance for the application of new acridone derivatives to be developed for the potential treatment of CML.

\section{Materials and Methods}

\subsection{Reagents and Materials}

N-(2-(dimethylamino)ethyl)-1-((3-methoxybenzyl)amino)-5-nitro-9-oxo-9,10-dihydro-acridine-4carboxamide (8q) was synthesized by Zhang [4]. Z-VAD-FMK (a pan-caspase inhibitor) was purchased from Selleck (Shanghai, China). Human chronic myelogenous leukemia K562 cells were purchased from the Chinese Academy of Sciences Cell Bank. Human chronic myelogenous leukemia KCL-22 cells and K562 adriamycin-resistant cells (K562/ADR) were purchased from Zhen Shanghai and Shanghai Industrial Co., Ltd. (China). Iscove's Modified Dubecco's Medium (IMDM) and Fetal bovine serum (FBS) was purchased from Hyclone (Logan, Utah, USA). Cleaved Caspase-3 antibodies were purchased from Cell Signaling Technology, Inc. (Boston, Massachusetts, USA), Cleaved Caspase-9, 8 antibodies were purchased from Wuhan SanYing Co., Ltd. (Wuhan, China); other antibodies we used in this study were purchased from Beyotime Biotechnology (Shanghai, China). Annexin V-FITC/PI apoptosis detection kit, apoptosis and necrosis assay kit and cell cycle and apoptosis analysis kit were purchased from Beyotime Biotechnology (Shanghai, China). Formic acid (HPLC) was purchased from Tedia (Ohio, USA). Acetonitrile (HPLC) and methanol (HPLC) were purchased from Fisher (Waltham, Massachusetts, USA). 


\subsection{Apoptosis and Necrosis Detection Assay}

Cell early and late apoptosis were detected using the Annexin V-FITC/propidium iodide (PI) apoptosis detection kit. Cell apoptosis and necrosis were detected using an apoptosis and necrosis assay kit (Hoechst 33342 and PI). Both two assays were detected after $0-800 \mathrm{nM}$ of $\mathbf{8 q}$ treatment for $48 \mathrm{~h}$. The experimental procedure was followed according to the instructions of the manufacturer. Axio Observer 5 with an Apotome fluorescence microscope (Carl Zeiss AG, Oberkochen, Germany) was used to observe the effect of $\mathbf{8 q}$ on the apoptosis and necrosis of K562 cells.

\subsection{Metabolomics Analysis Conditions}

The extraction of samples and the detection of metabolites using a UPLC/Q-TOF MS method were completed as previously described [9]. The this study, K562 cells were exposed to $500 \mathrm{nM}$ of $8 \mathbf{8 q}$.

\subsection{Flow Cytometric Analysis for Cell Cycle}

For cell cycle analysis, K562 cells were seeded in a six-well plate and incubated for $12 \mathrm{~h}$ following treated with graded concentrations of $\mathbf{8 q}$ for $48 \mathrm{~h}$. Cells were collected and washed twice by phosphate buffered saline (PBS), then fixed in ice cold 70\% ethanol. Cells were stained with $4 \mathrm{mg} / \mathrm{mL}$ PI and $0.1 \mathrm{mg} / \mathrm{mL}$ RNaseA in PBS. After incubation in the dark at room temperature for $30 \mathrm{~min}$, samples were subjected to flow cytometric analysis.

\subsection{Western Blotting}

K562 cells were cultured in $6 \mathrm{~cm}$ dishes, followed by treatment with $8 \mathrm{q}$ for different concentration periods for $48 \mathrm{~h}$. Proteins were separated by electrophoresis on an $8-12 \%$ Sodium dodecyl sulfate (SDS) polyacrylamide gel and transferred to polyvinylidene difluoride membranes. The membranes were blocked with $3 \%$ bovine serum albumin and then incubated with primary antibodies, followed by a horseradish peroxidase conjugated secondary antibody and detected by the Luminescence Image Analyzer Tanon 5200.

\subsection{The Vitro Anti-Proliferative Assay}

KCL-22 cells and K562/ADR cells were seeded into 96-well plates at 0.8-1.6 $\times 10^{4}$ cells/well, treated with compound $\mathbf{8 q}$. After 48 or $72 \mathrm{~h}$ treatment, the cells were incubated with $15 \mathrm{~mL}$ MTT (3-(4, 5-dimethyl-thiazol-2-yl)-2, 5-diphenyl-tetrazolium bromide from Sigma) solution ( $5 \mathrm{mg} / \mathrm{mL}$ ) for $4 \mathrm{~h}$ at $37^{\circ} \mathrm{C}$ with $5 \% \mathrm{CO}_{2}$. The formazan precipitates were dissolved in $100 \mathrm{~mL}$ DMSO. At $490 \mathrm{~nm}$, the absorbance was measured by InfiniteM1000 PRO (TECAN).

\subsection{Homology Modeling}

The amino acid sequence of homo sapiens CDK4 (GI: 49457488) was retrieved from the NCBI website. The crystal structure of homo sapiens CDK6 [23] in active form was retrieved in protein data bank serve (PDB ID: 2EUF), and employed as the template to build the 3D structure of the active form of CDK4. The sequence of the template and CDK4 were aligned, having $71.3 \%$ sequence identity. A reliable homology model of CDK4 was predicted using Molecular Operating Environment (MOE, Chemical Computing Group, Montreal, QC, Canada). Protein geometry was checked by Ramachandran plot.

\subsection{Molecular Docking}

The molecular docking was performed on Gold suite v5.2.2 (Cambridge Crystallographic Data Centre Software Ltd., Cambridge, UK), with default genetic algorithm settings [24,25]. Docking was performed without a reference ligand. The active site residues, Ile12, Gly13, Val20, Lys22, Ala33, Val72, Arg73, Leu74, Phe93 Thr102, Glu144, Asn145, Leu147, Ala157 and Asp158, were selected as a binding pocket. Gold Score was used as the fitness function for selecting the best docked conformation of the ligand. 
Supplementary Materials: Supplementary materials can be found online at http://www.mdpi.com/1422-0067/21/ 14/5077/s1.

Author Contributions: Conceptualization, B.Z. and N.W.; methodology, B.Z. and N.W.; software, H.-X.J.; validation, T.Z., T.-Y.Z.; writing-original draft preparation, B.Z.; review and editing, N.W., S.H., B.W. and H.-X.J.; All authors have read and agreed to the published version of the manuscript.

Funding: This research was funded by the financial supports from the National Key Research and Development Program of China (2018YFC0310900), the Natural Science Foundation of Ningbo City (2018A610410, 431902022), Foundation of Ningbo University for Grant (XYL18004, 421709410 and XYL20023), the National 111 Project of China (D16013), the Li Dak Sum Yip Yio Chin Kenneth Li Marine Biopharmaceutical Development Fund, and the K.C. Wong Magna Fund in Ningbo University.

Acknowledgments: We appreciate C. Benjamin Naman (Ningbo University) and Dawoon Jung (Ningbo University) for careful the editing of, and thoughtful comments about, the manuscript.

Conflicts of Interest: The authors declare no conflict of interest. The funders had no role in the design of the study; in the collection, analyses, or interpretation of data; in the writing of the manuscript, or in the decision to publish the results.

\section{References}

1. Miranda-Filho, A.; Piñeros, M.; Ferlay, J.; Soerjomataram, I.; Monnereau, A.; Bray, F. Epidemiological patterns of leukaemia in 184 countries: A population-based study. Lancet Haematol. 2018, 5, e14-e24. [CrossRef]

2. Soverini, S.; De Benedittis, C.; Mancini, M.; Martinelli, G. Best Practices in Chronic Myeloid Leukemia Monitoring and Management. Oncologist 2016, 21, 626-633. [CrossRef] [PubMed]

3. Kaehler, M.; Nagel, I.; Bruckmüller, H.; Boehm, R.; Ammerpohl, O.; Cascorbi, I. Abstract 5846: Drug resistance in chronic myeloid leukemia: Impact of methylation on gene expression in imatinib and nilotinib resistance. Cancer Res. 2018, 78, 5846.

4. Zhang, B.; Wang, N.; Zhang, C.; Gao, C.; Zhang, W.; Chen, K.; Wu, W.; Chen, Y.Z.; Tan, C.; Liu, F.; et al. Novel multi-substituted benzyl acridone derivatives as survivin inhibitors for hepatocellular carcinoma treatment. Eur. J. Med. Chem. 2017, 129, 337-348. [CrossRef] [PubMed]

5. Zhang, B.; Chen, K.; Wang, N.; Gao, C.; Sun, Q.; Li, L.; Chen, Y.Z.; Tan, C.; Liu, H.; Jiang, Y. Molecular design, synthesis and biological research of novel pyridyl acridones as potent DNA-binding and apoptosis-inducing agents. Eur. J. Med. Chem. 2015, 93, 214-226. [CrossRef]

6. Cui, Z.; Li, X.; Li, L.; Zhang, B.; Gao, C.; Chen, Y.; Tan, C.; Liu, H.; Xie, W.; Yang, T.; et al. Design, synthesis and evaluation of acridine derivatives as multi-target Src and MEK kinase inhibitors for anti-tumor treatment. Bioorganic Med. Chem. 2016, 24, 261-269. [CrossRef]

7. Arlin, Z.A. A Special Role for Amsacrine in the Treatment of Acute Leukemia. Cancer Investig. 1989, 7 , 607-609. [CrossRef]

8. Zhang, B.; Li, X.; Li, B.; Gao, C.; Jiang, Y. Acridine and its derivatives: A patent review (2009-2013). Expert Opin. Ther. Pat. 2014, 24, 647-664. [CrossRef]

9. Wang, N.; Zhang, B.; Jin, F.; Gao, D.; Liu, F.; Liu, H.; Jiang, Y. Combing metabolomics with bioanalysis methods to study the antitumor mechanism of the new acridone derivative 8q on CCRF-CEM cells: 8q induced mitochondrial-mediated apoptosis and targeted the PI3K/AKT/FOXO1 pathway. J. Pharm. Biomed. Anal. 2018, 160, 314-322. [CrossRef]

10. Chan, C.Y.; Zhao, H.; Pugh, R.J.; Pedley, A.M.; French, J.; Jones, S.A.; Zhuang, X.; Jinnah, H.; Huang, T.J.; Benkovic, S.J. Purinosome formation as a function of the cell cycle. Proc. Natl. Acad. Sci. USA 2015, 112, 1368-1373. [CrossRef]

11. Yin, J.; Ren, W.; Huang, X.; Deng, J.; Li, T.; Yin, J. Potential Mechanisms Connecting Purine Metabolism and Cancer Therapy. Front. Immunol. 2018, 9, 1697. [CrossRef] [PubMed]

12. Han, J.M.; Kim, J.Y.; Kim, S. Molecular network and functional implications of macromolecular tRNA synthetase complex. Biochem. Biophys. Res. Commun. 2003, 303, 985-993. [CrossRef]

13. Gomez, M.A.R.; Ibba, M. Aminoacyl-tRNA Synthetases. RNA 2020, 69, 617-650. [CrossRef]

14. Liang, F.; Kelly, S.; Suk, N.; Alexandre, A.; Carla, P.; Lennart, R.; Debra, T.H.; Dieter, S.L. Aminoacyl-tRNA synthesis by pre-translational amino acid modification. RNA Biol. 2004, 1, 15-19.

15. Liu, W.; Jin, F.; Gao, D.; Song, L.; Ding, C.; Liu, H. Metabolomics analysis reveals aminoquinazolin derivative 9d-induced oxidative stress and cell cycle arrest in A549 cells. RSC Adv. 2017, 7, 13149-13158. [CrossRef] 
16. Zha, C.; Deng, W.; Fu, Y.; Tang, S.; Lan, X.; Ye, Y.; Su, Y.; Jiang, L.; Chen, Y.; Huang, Y.; et al. Design, synthesis and biological evaluation of tetrahydronaphthyridine derivatives as bioavailable CDK4/6 inhibitors for cancer therapy. Eur. J. Med. Chem. 2018, 148, 140-153. [CrossRef]

17. Harper, J.W.; Adami, G.R.; Wei, N.; Keyomarsi, K.; Elledge, S.J. The p21 Cdk-interacting protein Cip1 is a potent inhibitor of G1 cyclin-dependent kinases. Cell 1993, 75, 805-816. [CrossRef]

18. Jansen, V.M.; Bhola, N.E.; Bauer, J.A.; Formisano, L.; Lee, K.M.; Hutchinson, K.E.; Witkiewicz, A.K.; Moore, P.D.; Estrada, M.V.; Sánchez, V. Kinome-wide RNA interference screen reveals a role for PDK1 in acquired resistance to CDK4/6 inhibition in ER-positive breast cancer. Cancer Res. 2017, 77, 2488-2499. [CrossRef]

19. Goel, S.; DeCristo, M.J.; McAllister, S.S.; Zhao, J.J. CDK4/6 Inhibition in Cancer: Beyond Cell Cycle Arrest. Trends Cell Biol. 2018, 28, 911-925. [CrossRef]

20. Tian, Y.-Z.; Liu, Y.-P.; Tian, S.-C.; Ge, S.-Y.; Wu, Y.-J.; Zhang, B.-L. Antitumor activity of ginsenoside Rd in gastric cancer via up-regulation of Caspase-3 and Caspase-9. Pharmazie 2020, 75, 147-150.

21. Indran, I.R.; Tufo, G.; Pervaiz, S.; Brenner, C. Recent advances in apoptosis, mitochondria and drug resistance in cancer cells. Biochim. Biophys. Acta (BBA) Bioenerg. 2011, 1807, 735-745. [CrossRef] [PubMed]

22. Médoc, M.; Dhilly, M.; Matesic, L.; Toutain, J.; Krauseheuer, A.M.; Delamare, J.; Fraser, B.H.; Touzani, O.; Barré, L.; Greguric, I. The vivo evaluation of radio fluorinated caspase-3/7 inhibitors as radiotracers for apoptosis imaging and comparison with [18F] ML-10 in a stroke model in the rat. Mol. Imaging Biol. 2016, 18, 117-126. [CrossRef] [PubMed]

23. Lu, H.; Schulze-Gahmen, U. Toward Understanding the Structural Basis of Cyclin-Dependent Kinase 6 Specific Inhibition. J. Med. Chem. 2006, 49, 3826-3831. [CrossRef] [PubMed]

24. Verdonk, M.L.; Cole, J.C.; Hartshorn, M.J.; Murray, C.W.; Taylor, R.D. Improved protein—Ligand docking using GOLD. Proteins Struct. Funct. Bioinform. 2003, 52, 609-623. [CrossRef]

25. Tan, K.-L.; Bin Ali, A.; Du, Y.; Fu, H.; Jin, H.-X.; Chin, T.-M.; Khan, M.; Go, M.-L. Synthesis and Evaluation of Bisbenzylidenedioxotetrahydrothiopranones as Activators of Endoplasmic Reticulum (ER) Stress Signaling Pathways and Apoptotic Cell Death in Acute Promyelocytic Leukemic Cells. J. Med. Chem. 2014, 57, 5904-5918. [CrossRef] 